\title{
EXPERIMENTAL CHARACTERIZATION OF THE PERFORMANCES OF A STORAGE EXCHANGER WITH TUBE BANK AIR-PHASE CHANGE MATERIALS
}

\author{
S. Ekomy Ango1,*, D. Bruneau², P. Sebastian ${ }^{3}$, R. Moutou Pitti ${ }^{4}$ \\ 1,4 INSTITUT DE RECHERCHES TECHNOLOGIQUES (IRT) B.P.14070 IRT, LIBREVILLE, GABON \\ 2 LABORATOIRE I2M (UMR 8508) ARTS ET METIERS PARIS TECH - BORDEAUX, FRANCE \\ 3 EsPlanade DEs ARTS ET METIERs 33405, TALENCE CEDEX, FRANCE \\ E-mail addresses :1 ekomyango@yahoo.fr, ${ }^{2}$ denis.bruneau@u-bordeaux.fr, 3 patrick.sebastian@u-bordeaux.fr, \\ 4 rostandpitti@yahoo.fr
}

\begin{abstract}
This study aims to show the preliminary results of an improved components and characteristics of heat exchanger air and Phase Change Material (PCM)that was designed, dimensioned, manufactured and tested in the laboratory (with melting temperature ranging between $27-29^{\circ} \mathrm{C}$ ), especially for refreshing semi-passive air in summer period. The preliminary results show that one of the exchanger's storage of the system manages to refresh the air during about 8 - 10 hours. About 7-8 hours are needed to regenerate the PCM. The current $(0.8)$ and the theoretical load lose (1) are appreciably the same. This system was integrated into a prototype of solar house of positive energy that has already been presented in Madrid in June 2010 during inter- university competition on Solar Decathlon in Europe (http://www.napevomo.com, www.sdeurope. org). Since there are still some issues with the ability of the containers system of the PCM to fill, drain, and dilate and conduct energy therefore further study may have to focus on the development of simulation model to overcome such weakness.
\end{abstract}

Keywords: Air conditioning; Residential building; Modelling; Free-cooling; Phase change material

\section{INTRODUCTION}

Since antiquity, the process based on free-cooling of the buildings by the thermal storage of energy in phase change materials (PCM) has always been used [1]. The principle of such process is based on the following phases: i) during the day, the phase change material absorbs the surplus thermal energy when the temperature of the air in the building exceeds its melting point. At this melting point (phase shift) the air can be cooled off, ii) at night, the current of draught from outside the building cools off and solidifies the PCM.

Over the years, two methods of storage of energy in building using the PCM have been developed [1-4]. In the first method, the fact that PCM is contained in the walls and/or the internal partitions of construction brings several issues. Among the well-known issues include the limitation of the total mass due to space constraint that result in the inability of the storage systems to transfer heat to the PCM during the day, and to evacuate its latent heat at night.

Regarding the second method, the PCM is considered as a promising air storage system. It represents an integral part of a heat exchanger air. This storage system has several advantages including the nonlimitation of the total mass because of its large space capacity. This allows the storage systems to transfer heat to the PCM during the day, and to evacuate easily its latent heat at night. It has also an ability to use the PCM "in bulk". Despite the above mentioned advantages, the second storage system is poorly used in practice. In addition, few studies have focused on further understanding of the components and characteristics of the second method.

This study therefore aims at highlighting the preliminary results on the components and characteristics of this second method on a basis of the storage exchanger with tube bank that was manufactured. 


\section{PRESENTATION OF THE STORAGE EXCHANGER WITH TUBE BANK}

The exchanging air-PCM is composed of two units (figure 1):

- a system of encapsulation of the PCM (authorizing the widening of the storage system over the melting point temperature or phase shift) associated with a system of dedicated filling;

- an air circuit that allows air's circulation to exchange heat with the PCM (air circuit).

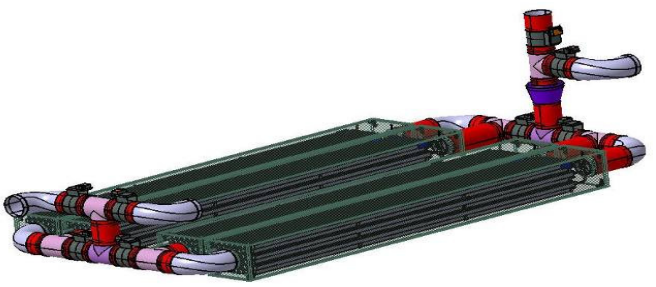

Fig. 1. Schematic representation of a portion of the storage system

\subsection{The system of encapsulation of the PCM}

The system of encapsulation is composed of a beam of forty-two tubes that are laid out in staggered rows. The tubes are made of aluminum. They are $3.41 \mathrm{~m}$ in length with external section $40 \mathrm{~mm} \times 20 \mathrm{~mm}$ (figure 2). The walls of these tubes are $2 \mathrm{~mm}$ thick. The deflectors (plates folded in "L") are stuck on the horizontal faces of the tubes and they play a baffle's role by imposing the air to carry a tortuous course. This has for result to increase heat exchange within the exchanger. A space of $10 \mathrm{~mm}$ length has been made horizontally between two tubes where in the air can circulate.

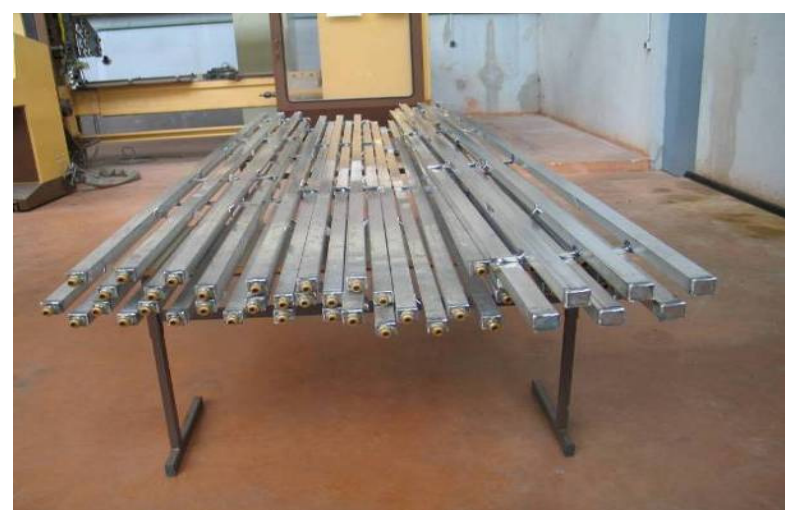

Fig. 2. Tubes column

At the end of each tube, there are connecters binding both tubes together. All the copper tubes are connected by elbows and pipe T. They contribute to form a system of filling and dilating devices (figure 3).

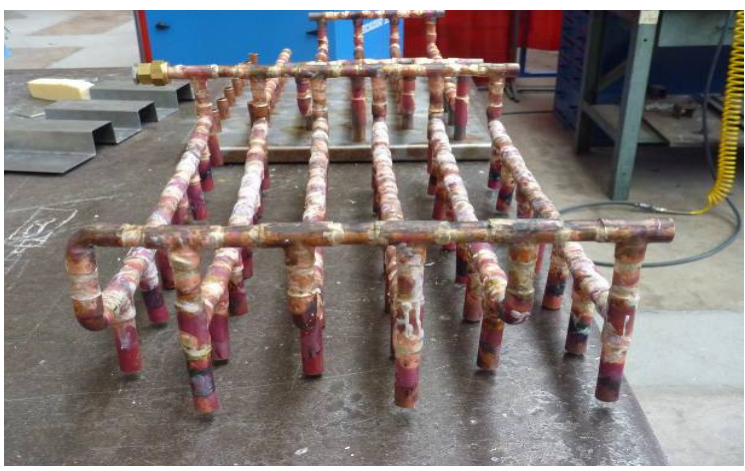

Fig. 3. Filling and dilating device

In two places, this system of filling is partially widening to allow the PCM system to dilate. This happens during the change of phase also known as cast iron phase or solidification phase (Figure 3). The tube bank, composed of 7 columns of 6 tubes, is connected by a U-shaped external part and a filling and dilating system (figure 4).

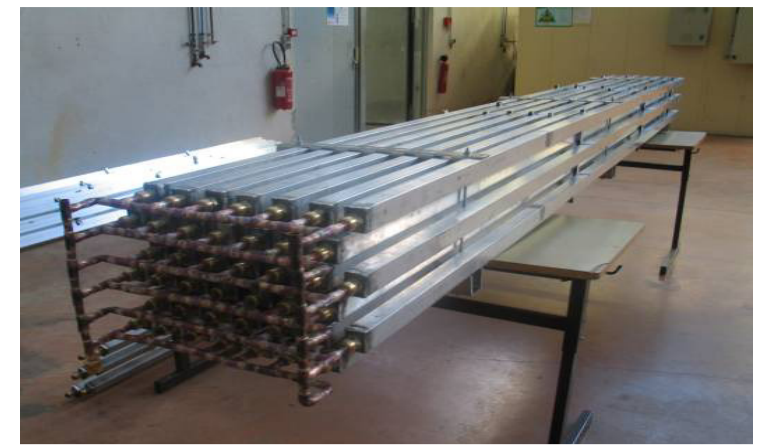

Fig. 4. System of encapsulation of the PCM: tube bank and its device of filling

\subsection{Air circuit}

The system of encapsulation of the PCM is installed in a wooden box (figure 5). The encapsulation system is called "box PCM" which is connected to an air circuit made of a collection sheath and a repression sheath. The latter two materials are used to connect the entry of the box PCM to the collection zone of air of the building on one hand and the exit of this box at the zone of repression of air of the building on the other hand. These sheaths have $200 \mathrm{~mm}$ of diameter.

When several exchangers are bound together and are in parallels, equilibrium valves are added to control the distribution of air flows. The use of the MVC (Controlled Mechanical Ventilation) contributes to add more lost load during heat exchange in the exchanger. 


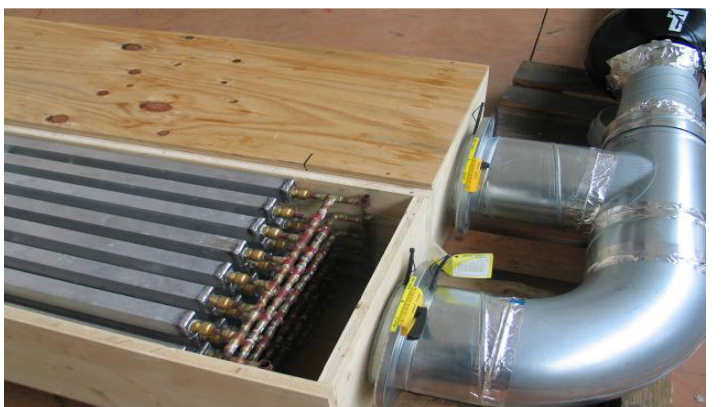

Fig. 5. Associated aerodynamics equipment: system of encapsulation in its box wood, sheath of connection and VMC

\section{CHARACTERIZATION OF THE STORAGE EXCHANGER WITH TUBE BANK}

\subsection{Instrumentation of Box PCM}

The experimental device is composed of a box B containing a beam of forty-two tubes $\mathrm{C}$. The latter are filled up with MCP RT 28 pure HC with melting point set around $28^{\circ} \mathrm{C}$ (manufacturer value). Three thermocouples named T1, T2, T3 are installed on this box to measure the change of the temperature throughout the tests. A ventilator D is installed at the entrance of box, which contributes to create a current of forced air. It is connected with a variation of tension, which enables to vary the speed of the ventilator. On both sides of the ventilator, two thermocouples called T4 and T5 are laid down to measure the change of the temperatures. For speed of air measurements, the load lost of the circuit is measured as follow: $\Delta \mathrm{P}=\mathrm{P} 1-\mathrm{P} 2$.

The experimental protocol is described as follow. The air is collected in the E zone then circulates in the PCM box before being rejected into the $\mathrm{A}$ zone. To estimate the mean value of air speed the PCM box at the entry point (V1) and exit point (V2) are measured. These measurements allow to calculate the volume of the air throughout the PCM box. Speed of retailers is obtained by dividing the volume throughout the PCM with the section of the tubes at entry and exit points of the PCM box as indicated by the following equation 1 [6] [7].

$$
v_{d}=\frac{q_{v}}{S}=\frac{1}{S} \sum \pi\left(R_{i}^{2}=R_{i-1}^{2}\right) \cdot v_{i}
$$

\subsection{Results and discussions}

Figure 7 represents the temporal changes of components of Phase Change Material (PCM) in relation to temperatures of the experimental device.

Figure 8 indicates the temporal changes of the efficient of the cooling of the experimental by temperature. The efficient of cooling is the relationship between the difference of the temperature of fusion at entry and exit points of the PCM (Equation 2).

$$
\varepsilon=\frac{T_{1}-T_{2}}{T_{1}-T_{m c p}}
$$

Figures 7 and 8 show that time of cooling off the PCM system falls between 8 to 9 hours. This cooling phase is reached on four specific phases:

(1) a phase of under cooling wherein the metal and the PCM are initially at a temperature lower than the melting point of the PCM. The cooling off phase is achieved because of the significant heatstorage capacity of the metal. There is a fast rise of the temperature $\left(30^{\circ} \mathrm{C}\right)$ in a very short period of time about 20 to 30 minutes). In 15 minutes only, there is a fast reduction of the cooling off efficiency from 1,3 to 0,9 .

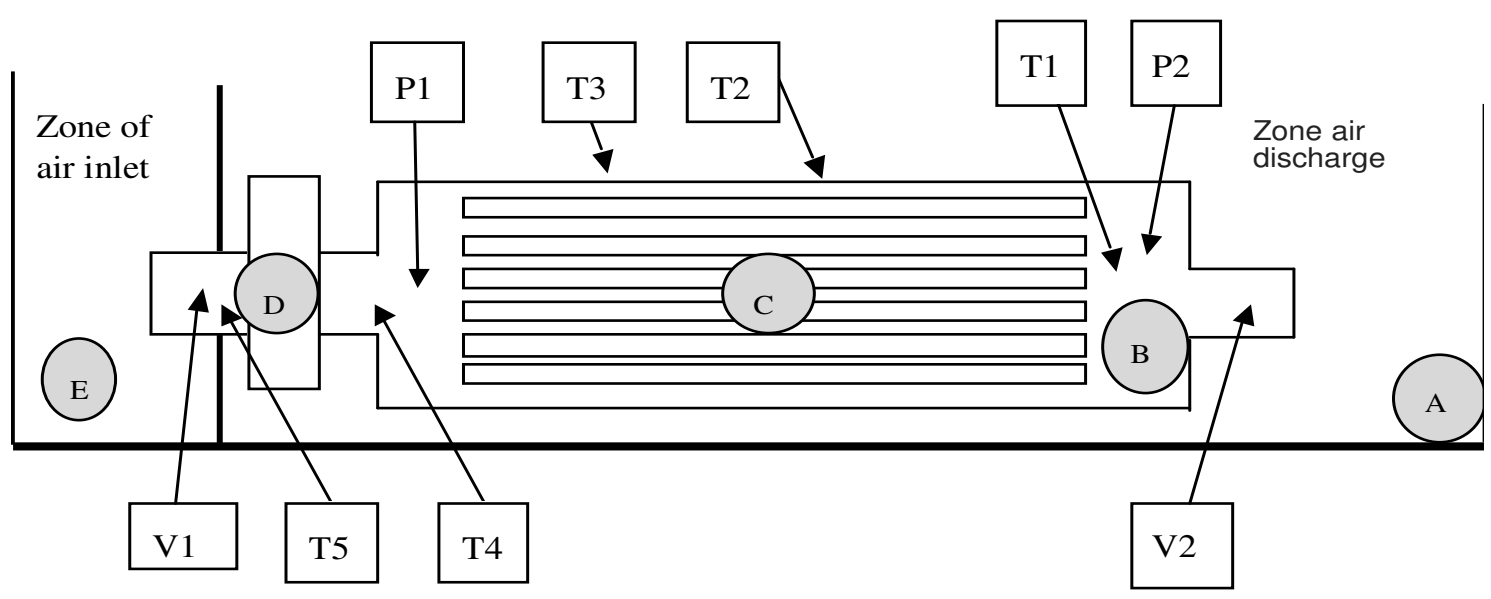

Fig. 6. Experimental device 


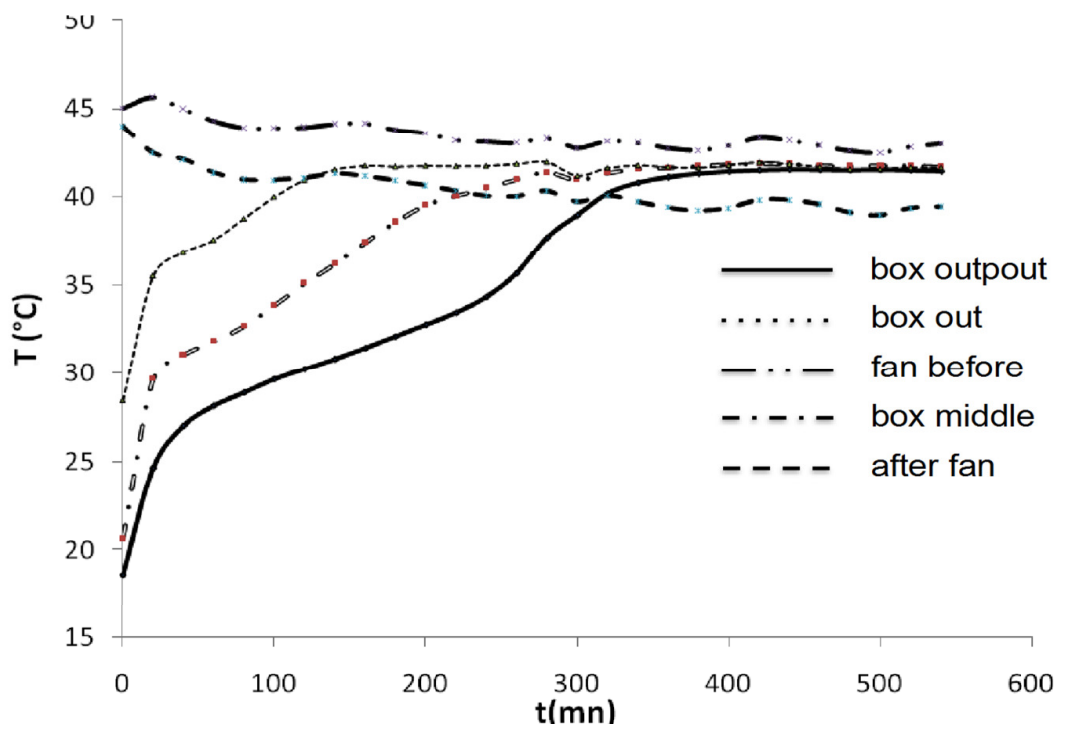

Fig. 7. Temporal changes of the characteristics of the PCM by temperatures

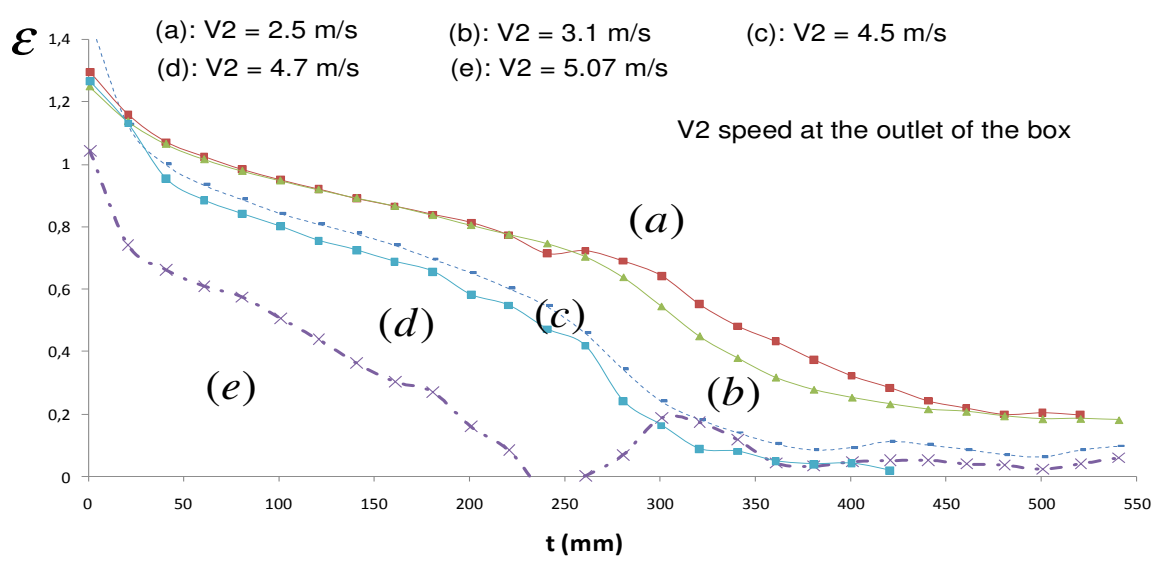

Fig. 8. Contour and area around the crack tip

(2) a phase of fusion happens during this phase. At that phase, the PCM is colder than the metal. The cooling of the air is caused by the fusion of the metal material with phase shift. As indicated in figure 7, cooling off phase is reached gradually and the temperature passes from $30^{\circ}$ to $38^{\circ} \mathrm{C}$ in only 300 minutes. On the contrary, the efficiency of the cooling off phase decreases more gradually (from 0.9 to 0.2 ) than the first phase in 320 minutes.

(3) a phase of overheating. The PCM finishes its fusion. At this phase, the temperature of the air rises because of the significant heat capacity of the metal. The temperature increases quickly from $39^{\circ} \mathrm{C}$ to $42^{\circ} \mathrm{C}$ in only 30 minutes. On the contrary, cooling off phase will decrease quickly from 0.2 to 0.1 in just 20 minutes.

(4) an equilibrium phase. This phase is reached because of the lost of heat that were initially encapsulated from in the walls and/or the internal partitions of construction.

\section{CONCLUSIONS}

It is worth mentioning that the preliminary results of the study on storage of energy of the components and characterization of the storage exchanger with tube bank (PCM) are very encouraging. Among the outstanding results include the fact that one of the exchangers storage of the system has managed to refresh the air during about 8 - 10 hours like agreed. In addition, the exchanger's storage of the system has also contributed to regenerate the PCM on about 7-8 hours. Among other strength of this study includes the fact that, there are almost not variations between the current (0.8) and the theoretical load loses (1). The usefulness of such storage system is to better enhance people's comfort in their homes and reduce heat peak 
during summer period. Among the perspectives, future studies have to focused on developing a simulation model [8] that will more likely contribute to improve the technological solutions related to the inability of the PCM containers system to fill, drain, dilate as well as to properly conduct energy flows through out of the system.

\section{REFERENCES}

[1] Yinping Z., Guobing Z., Kunping L., Qunli Z. Hongfa D. "Application of latent heat thermal energy storage in buildings", Building and environment (42), 2197$2209,2007$.

[2] Saso M., Ciril A. "Correlation between the climatique and the free-cooling potential of latent heat storage", Energy and building, 429-437, 2007.

[3] Regin A.F., Solanki S.C., Saini J.S., "Heat transfer characteristics of thermal energy storage system using PCM capsules: a review", Renewable and Sustainable Energy Reviews (12), 2438-2458, 2008.

[4] Verma P., Varun, Singal S.K. "Review of mathematical modeling on latent heat thermal energy storage systems using phase-change material", Renewable and sustainable energy reviews (12), 999-1031, 2008.

[5] Serge E. A. "Contribution au stockage d'énergie thermique en bâtiment: développement d'un système actif à matériaux à changement de phase", Thèse arts et Métiers ParisTech, Talence, France, 2011.

[6] Recknagel H., Sprenger E., Honmann S. "Manuel pratique de génie climatique", PYC Edition Paris. ISBN 285330084 6, 115-116, 1986.

[7] Idel'clik .E.I. "Mémento des pertes de charge", Collection des directions des études et recherches d'électricité de France, 1981.

[8] Fabien R., Denis B., Patrick S., Serge E. A., Jérôme L. "Numerical modeling and experimental study of a box-section tube bundle thermal energy storage for free-cooling of buildings", Innostock, 2012.

[9] Onyejekwe D.C., "Design and thermal analysis of a solar powered cold storage ware-house using a phase material ", Nigerian Journal of Technology Vol. 13, No.1, 1989. 